\title{
The Stimulation of Written Texts in Students from Espiritu Santo University through the Scientific Communication and Research Methodology Classes
}

\author{
Yeimer Prieto-Lopez \\ Universidad Espiritu Santo \& Unidad Educativa Bilingue Torremar, Guayaquil, Ecuador \\ Fabricio Ayala-Pazmino \\ Unidad Educativa Bilingue Torremar, Guayaquil, Ecuador
}

\begin{abstract}
In this paper, a theoretical-methodological analysis was conducted on the teaching of the construction of written texts in The Espiritu Santo University (UEES, in its Spanish acronym) Scientific Communication classes, with an interdisciplinary nature, conceived from the bibliographic review and the use of updated criteria on the subject. As a result, the aim is to explain the importance of textual construction as an interdisciplinary ability. The need for the application of this functional component was demonstrated not only by specialized teachers of Language and Communication but of other subjects such as Research Methodology and Academic Writing. It also became evident that they constitute a cognitive domain that is common in the work of all the subjects and a pillar on which the efficiency of communication is based, while it also promotes essential skills for the performance of education professionals, as well as competences in communication and research.
\end{abstract}

Index Terms - higher education, teaching-learning process, language and communication, research methodology, critical thought, textual construction, interdisciplinary abilities

\section{INTRODUCTION}

Language is an essential part of identity, an expression of a people's culture, and a pillar of nationality, but most importantly, educators are aware that it is an effective mean for the creation of thought and communication. The construction of texts in the mother tongue is essential to learn different subjects and has a primary role in education. Therefore, the objective of this work is to explain the importance of textual construction as an interdisciplinary ability and competence. In attempting to achieve this objective, an overview of the main components of the writing and review process are presented, and insight into the content of each significant phase of writing to producing work is offered based on evidence and expertise in the field.

The bonding subjects and project follow-up, as part of the discipline of Communication and Research Methodology, are established as the interdisciplinary macro axis that is a source of multiple knowledge, essential in the learning of all subjects. Hence, the need for pedagogues to insist on the outstanding role of language in the transmission and assimilation of knowledge in classes and outside them. Reading and its comprehension, oral and written communication, spelling, and vocabulary, are all cognitive domains that are common in the work of all the subjects and pillars upon which the efficiency of communication is based. These are abilities that are necessary for the professional performance of education. However, at its most fundamental level, writing is the expression of thought, and this expression represents the level of knowledge and understanding a student has on a particular subject (Carter, Salamonson, Ramjan \& Halcomb, 2018).

At present, the challenge is to develop in the students of UEES the communication and investigative competencies through the construction of written texts from different interdisciplinary subjects, where Research Methodology, Scientific Communication, and Language and Communication stand out. We intend this research to contribute to the training of competent professionals who express themselves eloquently, elegantly, and that extrapolate all this in written language through papers, essays, and scientific articles. The remainder of this document contains an overview of the writing process, including the development stage, planning, the actual written production of the work, review, orientation stage, execution state, and control. This document then concludes with a summary and outline of key points.

\section{The Writing Process}

\section{Development}


This research work is a valid document, from a theoretical and a methodological point of view, for the teaching of textual production aimed at teachers specialized in language and other disciplines. It focuses on the need to understand textual construction as a process where teachers and students must pass through different stages and phases. For its development, specialized bibliography on the subject was consulted (García-Alzola, 1975; Repilado, 1975; Grass, 2003; de Beaugrande, 1994; Hayes, 1996; Cassany,1999; and Roméu, 2007, among others) and more updated criteria of Ortiz, 2010 and Roméu, 2011 was used. Each of these works, produced in Spanish, represents a seminal presentation of the conceptual process underpinning writing and its purpose. Each was also included because of its implications for bilingualism and the communicative differences that exist when translating text or learning a new language.

The current conception of language teaching in Higher Education is based on the cognitive-communicative and sociocultural approach, defined as:

"[...] a psychological configuration that encompasses cognitive and metacognitive abilities to understand and produce meanings, knowledge about linguistic and discursive structures, and the skills and abilities to interact in diverse socio-cultural contexts, for different aims and purposes. This articulates the cognitive and metacognitive processes, the mastery of discursive structures, and the socio-cultural performance of the individual, which implies his or her personal development (cognitive, affective-emotional, motivational, axiological, and creative)" (Cassany, 1997). This quote reflects the cognitive and communicative link both conceptually and physiologically, whereby a thought underpinned by activation of the prefrontal cortex signals the transmission of an impulse to elicit production via some physical medium, whether it be vocally, through writing, or via the use of a word processor (Hathaway, 2015). Regardless of the medium, writing is communication and reflects the dissemination of human emotion to others (Carter et al., 2018).

This focus methodologically supports the understanding, the analysis, and the construction of texts, functional components that are part of any subject of the curriculum. For the application to be practical, it is necessary to begin with the discovery of the value and functionality of the linguistic resources used; as well as to promote their analysis in situations where humans interact and participate with different purposes. Furthermore, it is necessary to confront students with dissimilar texts constructed in different functional styles, so they can understand the need to choose the appropriate code for their style of communication, as well as the communicative intention in order to construct texts more authentically and creatively. Presenting a diverse range of sources in a progressive and increasingly challenging manner can produce complexity and depth of learning, which is more transferrable to a range of educational contexts and settings (Huisman, Saab, van den Broek \& Van Driel, 2019).

Text construction is a common component that all subjects must tackle in the careers of the UEES. With the help of a teacher and independently, students must write short and coherent texts of a narrative, descriptive, expository, and dialogued nature, as well as the production of different types of summaries. Despite the actions carried out, these still do not satisfy the expectations of the study plan, as well as the scientific writing of the Research Projects and Subject Projects. However, many students struggle with this process and require an individualized understanding of their communicative levels to maximize the learning process. Writing and text construction is an essential component of all aspects of higher education but must be effectively combined with applied learning scenarios whereby students are allowed to communicate dynamically with one another and critically reflect on what has been learned (Hathaway, 2015).

The management of the construction of different types of texts requires the teacher to have a deep mastery of the content in order to guide the development. The essential requirements to achieve this are to be a great communicator, have professional abilities, and bear a comprehensive general culture acquired through constant training, while at the same time bringing new knowledge and skills to their training, and systematically activating those already acquired. Additionally, this process allows teachers to more effectively guide students in the text construction process and produce more in-depth and more sophisticated knowledge of the subject matter (Hathaway, 2015).

Writing is a complex process that involves different operations that allow the person who writes to represent and communicate what he or she feels, thinks, and knows, as well as to better understand what he or she communicates. In other words, writing enables the communicator to mobilize and develop their thinking. Doing it under the conditions of a particular communicative situation implies, at a minimum, the management of a set of complex activities (the activation of the relevant linguistic and thematic knowledge or the organization of information according to the objectives and discursive aims) that are carried out in a particular way depending on the social and cultural context in which the production of writing makes sense. If the teacher can thoroughly understand this complicated process and the sociocultural context in which it occurs, then she or he will be a more effective educator and able to guide students through their learning and cognitive development.

Adjusting texts to the multiple demands and various communicative situations requires writers to clarify that the production of a text is the result of a long and complicated process in which there is evidence of several phases that go from planning to its edition, where each of these requires elements of cognitive essence. To write a draft and be done, do not reflect the complexity of the process sufficiently. Writing must be considered a process that is underpinned by multiple stages, completed not just by the writer but by peers, reviewers and editors. The first draft represents just the original expression of thought but does not illustrate the formal articulation of a complex concept or idea at this early stage.

The debate about text construction has created many models which focus either on products, their characteristics, and aims; or on processes that are at stake right up to their production. Each of these models contains distinct and 
independent assumptions about outcomes that occur when texts are constructed and developed in unique ways, and each may also be applicable in diverse settings and contexts. When referring to how writing has been oriented, an analysis should be made of the different models that have been used to do so. These models are representative of the different periods through which the teaching of textual construction has passed: as a product and as a process. In the analysis of text as a product, the study focused first exclusively on writing, and then as a process. In addition to the model driving the production of a text, the socio-cultural context in which it is produced must also be considered. A failure to do so would limit the transferability of what has been produced and also reduce the dissemination of the ideas being expressed to those who may find it valuable. For this reason, constructing text based on the use and application of sociocultural theory is critical to contemporary higher education.

Research has shown that the process is not linear because the text is done and continuously redone; it is planned and planned again; it is corrected, and so on. For these reasons, it appears it does not follow several discrete stages but a few subprocesses that interact. Currently, the topic specialists (Cassany, 1997; de Beaugrande, 1994; Hayes, 1996; among others) defend the existence of three stages: orientation, execution, and control, as well as three operations: planning, text production, and self-review. Each of these stages is discussed in greater detail below.

Textual construction is first and foremost a psycholinguistic process, which means that the text is constructed first in the mind, so it needs stimulation which is achieved when students are faced with writing in contexts and real and practical usage situations; therefore, the emphasis should not be placed on the formal or grammatical aspects of the language, but on the thought that is produced, obviously without abandoning linguistic aspects that facilitate communication. Writing represents just the mechanical aspect of this psycholinguistic process. A careful reviewer or editor can discern meaning from perhaps sophomoric, rudimentary or undeveloped writing styles and abilities and guide the student toward the more effective crafting of language in order to express her or his complex ideas and emotions. To reiterate what has been said above, textual construction has different phases, as shown by Cassany (2013), which we have had the opportunity to systematize as part of this research at UEES in the classes of Research Methodology and Scientific Communication, which are repeated and recreated in the act of writing. This is an example of what each phase consists of:

\section{Planning}

Before the act of writing, planning facilitates the creation and organization of the text. It is the moment when the student, from a particular communication situation, can create summary tables, conceptual maps or notes, and discuss with their classmates about what they want to write, or resort to reading different types of texts that facilitate its creation. Planning occurs cognitively and then via the formal construction of an outline for a particular text.

This preliminary phase can be stimulated by inviting students to think about what they want to write, in order to share it and enrich it with the input that their classmates can give them; also, they can be taught to create conceptual maps in which they represent their ideas in an orderly manner. The critical thing to consider within the planning process is to develop the habit of planning the text, in such a way that it leads them to think not only about what they are going to write but also about how to do it, the type of words to use, and the treatment they are going to give to the topics according to the recipients. While some teachers encourage students to write in order to stimulate the process, it is recommended that students always begin a work by constructing an outline first. This allows for the writing to be ordered, logical, coherent and flow naturally from one theme or point of discussion to the next. Additionally, once the outline is constructed, the text mostly writes itself. The following step is the actual writing, which is discussed in the following section.

\section{Writing}

Once planning is complete, the writer can then begin the actual production of the draft. The strategies used in the previous phase are the starting point for this phase; the requirement now is to organize what wants to be communicated, so the text clearly expresses the message. This is where the knowledge related to the topic, the language, and the recipients come together. It is the moment to make decisions related to the use of certain words, according to the textual typology, the communicative intention, and the context; it is also necessary to select the punctuation marks, the connectors, and the most suitable propositions. Teachers accompany students in this complex task of writing. Students should be made aware that the first draft they produce during this phase is by no means the last. Several drafts and reviews are needed in order to reach a point in which the text clearly represents the intent of the author. Students may develop writer's block when they believe that they must produce a highly sophisticated and formal written outcome during the first draft. With a well-constructed outline, the writer can address each point in multiple ways and continue to develop ideas while adhering to the same thesis. The review process is discussed in the following section.

\section{Review}

Once a draft has been produced, it must be reviewed by a third party. The review process is one of the most critical moments of text production. In this stage, the student, after reviewing and rewriting his or her text, becomes aware of the linguistic and cognitive aspects that must be considered to improve his or her written communication. The teacher can promote different pedagogical strategies that facilitate revision and self-correction; for this, it is essential to specify which aspects must be considered in order to achieve a "well written" text, that is, one that communicates ideas clearly. These components include textual superstructure, legibility, precision, concision, coherence, cohesion, grammatical correctness, and written fluency. Students must be encouraged to not overly self-correct when writing or they will 
develop writer's block. However, they should be encouraged to be self-critical during the review process and open to feedback from third-party reviewers. In this phase, it is essential that those who write become aware of their difficulties and the possibilities of overcoming these, it is not merely a question of pointing out or correcting faults; revision, therefore, must be an effective instrument for learning, it must be conceived as a more didactic technique and not as a compulsory control operation at the end of each text. During the review, students must understand that before publishing a text, they must develop as many drafts as necessary to guarantee the concept readability so that it communicates the intention with which it was written.

\section{Editing}

Once the review process is complete, it must be edited. When the message of the text is communicated, and it responds to the intention with which it was written, the textual construction process ends, then it is time for the audience to see it. Along with these phases, there are different stages through which the students and teachers must walk during this laborious process. To successfully face the task of writing, it is necessary to pay more attention to the different stages of text construction: before, during, and after, hence the need to think before writing, to generate ideas, and the critical role of pre-writing and re-writing: the fact that the student knows he or she can rectify what was written, which will give the student, without a doubt, confidence and assurance when writing. It is also important to mention that good writers plan the structure of the text, take notes, and they pause for a moment at all these aspects before they start writing, as mentioned by Cassany.

Orientation stage. It takes place during a class or can be extended. The student gathers data and information about the work. To this effect, the teacher must explore the student's knowledge about the subject and the motivation that drives him or her. From the proposition of the topic, we proceed to the exploration of the ideas. Through this activity, students:

1.- Express their ideas with independence, which contributes to the discovery of multiple significant variations of the topic.

2.- They learn new words that the teacher introduces from the observation of aspects ignored by reality.

3.- They practice while they develop the skill under study (for example, they orally carry out the operations needed to describe).

4.- They organize their ideas related to the topic and specify the subtopics or topics to be developed, which is the plan for the construction of the written text.

5.- They suggest a title.

During orientation, the teacher will warn about the possible errors which may incur regarding both content and form.

Execution stage. It does not necessarily take place during a class, as it can be directed as homework. During this stage, the student will write, for which he or she will take into consideration:

1.- The plan

2.- The specificity of the type of text he or she will construct

3.- The observations done by the teacher regarding the errors that can be made

4.- The self-evaluation of the work, which is expressed in dissatisfaction and constant interest in achieving a higher quality work (functional self-criticism). The teacher's attention to the students is essential, regarding their individual differences (progress of work, difficulties they have faced).

Control stage. The obtained result is verified. It is necessary to verify the quality of the work done by the students and how they have achieved their goals. It is recommended that each work is read at least three times: the first time to understand its global content and to value the alignment to the topic, the quality, sufficiency, and depth of the ideas; the second time to determine the quality of the lexical and grammatical means used, how coherence is achieved, the adjustment to orthographic norms, and presentation; and the third time for its more integral evaluation, keeping in mind the unity of the elements of content and form, depending on the intention and purpose of the author, as well as the evaluation of style.

The individual review can be done first with support and then independently. It can be of different types:

- Own review from the indicated errors, with the aid of symbols and a guide (self-review).

- The students may review their works and exchange and review that of a classmate.

The abilities to self-review and self-correct their works must be developed in a tiered and progressive way until the students master them.

The collective review in the classroom must be done in a pleasant environment, which will contribute it to be done in a positive sense, where the successes will stand out more than the errors. On the other hand, everyone must have the opportunity to give their opinions, give their assessments, and offer suggestions. The dissemination of the best works, through reading them in activities organized by the school or their public exhibition, helps to stimulate authors and serves as an incentive for those who are lagging.

\section{CONCLUSION}

The purpose of this document was to discuss both the importance of text construction in higher education and also the process of underpinning writing. Mastering the stages for the teaching of the construction of written texts is of the utmost importance, just as it is the mastery that the teacher and the student have of the phases of this process, in the 
same way, it is essential for teachers and students to walk together in this complex task because it is crucial not only to ask the student to write, but to stimulate, motivate, and accompany the student in this task.

\section{REFERENCES}

[1] Beaugrande, R. (2003). La saga del análisis del discurso. En Teun Van Dijk. El discurso como estructura y proceso. Barcelona: Editorial Gedisa S. A.

[2] Carter, R., Salamonson, Y., Ramjan, L. M., \& Halcomb, E. (2018). Students use of exemplars to support academic writing in higher education: An integrative review. Nurse Education Today, 65, 87-93. doi:10.1016/j.nedt.2018.02.038.

[3] Cassany, D. (1999). Construir la escritura. Barcelona: Paidós.

[4] García-Alzola, E. (2000). Lengua y literatura: Su enseñanza en el nivel medio. La Habana: Editorial Pueblo y Educación.

[5] Grass-Gallo, E. (2003). Textos y abordajes. La Habana: Editorial Pueblo y Educación.

[6] Hathaway, J. (2015). Developing that voice: locating academic writing tuition in the mainstream of higher education. Teaching in Higher Education, 20(5), 506-517. doi:10.1080/13562517.2015.1026891.

[7] Hayes, J. (2006). News Framework for Understanding Cognitive and Affect in Writing. Trad. De S. Bonilla. Barcelona: Ed. Ariel.

[8] Huisman, B., Saab, N., van den Broek, P., \& van Driel, J. (2019). The impact of formative peer feedback on higher education students' academic writing: A meta-Analysis. Assessment \& Evaluation in Higher Education, 44(6), 863-880. doi:10.1080/02602938.2018.1545896.

[9] Martí, J. (1990). Ideario pedagógico. La Habana: Editorial Pueblo y Educación.

[10] Repilado, R. (2005). Dos temas de redacción y lenguaje. La Habana: Editorial Pueblo y Educación.

[11] Roméu-Escobar, A. (2010). El enfoque cognitivo, comunicativo y sociocultural en la enseñanza de la lengua y la literatura. La Habana: Editorial Pueblo y Educación.

Yeimer Prieto-Lopez, PhD Doctor in Educational Sciences. Bachelor's degree in Education. Head Professor at the Espiritu Santo University (UEES, in its Spanish acronym) in the Faculty of Liberal Arts. Professor at the master's degree in Educational Management at UEES. Teacher and academic auditor at The Bilingual School Torremar. He has participated in several national and international events as a speaker. He has publications in indexed magazines. He has worked for more than fifteen years as a university teacher and has had different responsibilities, such as Director of the Doctoral Training at The University of Physical Culture and Sports of the City of Holguín. He has participated in more than twenty national and international conferences of Pedagogy, Education, and Didactics. He is the tutor of several doctoral theses at the Universidad del Rosario in Argentina. He has so far trained three Doctors of Science at the Court of Pedagogical Sciences in Cuba.

Fabricio Ayala-Pazmino He has degrees in Computer Science, Business Administration, Educational Sciences, and received his Ed.D. in 2018 from The University of Melbourne in Melbourne, Victoria, Australia, with his major concentration of study on languages other than English (LOTE), ESL, TESOL curriculum, pedagogy, and higher education. He currently works for The Bilingual School Torremar in Guayaquil, Ecuador as an educator and has experience as an Academic Coordinator and Teaching Associate for Hispanic Studies. His previous experience also includes working as head of the Humanities and the Community and Service Departments at Britanico International School in Quito, Ecuador. He was a lecturer at Monash University in Melbourne, Australia, and at De Las Americas University in Quito, Ecuador. Dr. Ayala is a current member of the Monash University Teaching Association for Hispanic Studies. 